\title{
Skills Analysis on the Set-Upper Movement in Volleyball
}

\author{
Agung Wahyudi ${ }^{1}$, Supriyono $^{2}$, Agus Pujianto $^{3}$, Imam Santosa $^{4}$, Maryadi $^{5}$ \\ \{agungwahyudi@mail.unnes.ac.id ${ }^{1}$, supriyono_pjkr@mail.unnes.ac.id ${ }^{2}$, \\ guspujianto.73@mail.unnes.ac.id $\left.{ }^{3}\right\}$ \\ Universitas Negeri Semarang, Semarang, Indonesia ${ }^{123}$
}

\begin{abstract}
The success of attacks in volleyball is determined by set-upper. The aim was to analyze the movement of the upper pass including footwork, arm motion, body movement, and hand motion. This qualitative research with survey methods has population where 15 female volleyball athletes and two set-upper were involved as samples using a purposive sampling technique. The Kinovea program was used to analyze and the results showed that the angle of the foot showed the correct movement, where the foot makes an angle and lowers the body to position it just below the ball object. The angle of the arm is well demonstrated in preparation for pushing the ball object both forward and backward, movement of the body parts as a whole shows positive motion, especially the ability to flex the body in the movement of the backset. The angle of the hand shows a very good movement of the ball.
\end{abstract}

Keywords: Volleyball, set-upper, sport biomechanic.

\section{Introduction}

Volleyball is a sport that is popular with the general public. This is proved by the frequent competitions that are held in cities and villages, men and women, young and old. Sports competed from the village, district, regional to national levels. The one of success factors of attacks in volleyball is determined by set-upper. This player even becomes the central attack in getting points. Often a volleyball team wins matches because it has good set-uppers. The setupper player is a volleyball player in a team who has the ability to pass and toss the ball to the players in one team so that it can be hit by the attacking player (spiker) to get points. The job of the set-upper is not easy, he must be smart in determining which attacking player decisions should be passed to get points, as well as considering and outwitting the opposing team in an attempt to stop the attack (blocking). The technique commonly used is overhead passing with a forward (front set) and backward (backset) bouncing direction. The strategic role of setupper players in the volleyball game requires a study related to analyze passing movement skills for set-upper players to get point faster based on biomechanical principles. The purpose of this study was to determine and analyze the movement of the upper pass including 1) footwork, 2) arm motion 3) body movement and 4) hand motion.

The principles of mechanics of human motion when carrying out sports activities are studied in biomechanics. Science concerns the body of living things and is a combination of applied mechanical disciplines. The application of biomechanics in sports is carried out to analyze movements so that the results of this analysis can be used to improve techniques 
effectively. Effective motion patterns will produce good technique. Coaches can analyze the efficiency of an athlete's movement and try to determine if the athlete can perform more movement.

\section{Literature Review}

Biomechanic. Biomechanics is closely related to a body movement or what is known as a motoric. The process of an initial movement starts with simple or gross motor movements to combination or fine motor movements. An athlete has passed this phase at an early age until he becomes an athlete. In its development, a movement can become more effective by using mechanical principles. Biomechanics is the study of the function and structure of biological systems using mechanical methods. The biomechanical approach to sports is more focused on sports actors (athletes), but the biomechanical approach to sports can also extend to the behavior of immovable objects such as footwear, surfaces (fields), and sports equipment that can affect athlete's performance. With advances in biomechanical analysis, technology can be done with the help of computers. Biomechanical analysis performed using a computer is usually done by examining the results of recorded training sessions or competitions conducted by athletes. From the results of biomechanical analysis, the data obtained is in the form of velocity and the angles of the athlete's joints during movement. The results of the analysis determine whether the athlete already has a good technique or not. Therefore, the importance of biomechanical analysis in sports is to increase the effectiveness of a movement that can be used by a coach to athletes. So that biomechanical analysis can produce professional athletes to advance sports in Indonesia and be able to compete with other countries.

Volleyball. Volleyball is a popular game in Indonesia. Volleyball is one that is used by the community both in achievement sports, educational sports, and recreational sports. Games that as a whole involve fast and strong body movements [1], played together in a team [2], and uses very narrow space (81 square meters for each team), requires very fast and dynamic action, technical characteristics, tactical, and allows non-verbal communication between players on the field [3]. This game is fun [4] because it can adapt to various conditions that arise, can be played any number (2-6 people), can be played on any surface, both indoors and outdoors, can be played at all ages, between genders, and volleyball requires few ground rules, little equipment, and is a popular recreational sport. The hallmark of the game of volleyball is bouncing the ball so it doesn't fall on the floor. Volleyball requires mastery of basic techniques in order to be able to play it well, namely movement skills that aim to solve a certain movement problem in the most economical and useful way. There are six basic techniques of volleyball: serve, take attacks, hit, pass, block, and receive serve. Servicing is the first shot [5], but its shape has resembled a spike on a jump serve [6]. The jump serve is widely used by both indoor and beach volleyball players [7], and the success of serving techniques in play are the main variables in the success of the match [8]. The basic techniques are almost the same form and the goal is the technique of receiving service and the technique of receiving the attack. this is known as the forearm pass and overhead pass [5]. The forearm technique is also known as the forearm pass or the bump [4].

Set-Upper. The overhead pass technique developed into a technical specialty, namely setting, including front-set, backset, lateral set, jump setting, one-hand set, forearm set [9]. The front- 
set is a set-upper technique where the ball is bounced in the direction of the bounce in front of the set-upper. A backset is a technique of passing in which the ball is bounced back to the setupper. The game of volleyball is a sport where individual success is achieved by harmonious collaboration from the efforts of other players [10] so that training sessions should be introduced. Play training sessions help athletes read the game and focus on what they see, when, and why [11]. Athletes are expected to be proficient in encoding specific domains and have the ability to predict games efficiently [12].

\section{Methods}

This research uses qualitative research with survey methods. The population in this study was 15 female volleyball athletes from Central Java for PON PAPUA 2021. Two set-upper players were involved as samples of this study using the purposive sampling technique. The Kinovea program tool is used to analyze front-set and backset motion based on biomechanical principles.

The video recording is processed using software to get motion photos. These photos are the result of video capture and made into frame-by-frame images. Each athlete's motion was photographed and then analyzed using Kinovea software to obtain the angle of movement of the legs, body, arms, and hands.

\section{$4 \quad$ Result and Discussion} follows:

The results of the analysis of the baiting movement skills research are presented as

\subsection{Front-Set Motion}

Preparation. The player starts the preparatory movement with an upright body position with the leg angle bent 100 degree. The result of this movement is that the body is brought under the ball so that the ball is within reach. The elbow flexes at 121 degree and the wrist performs an extension motion at an angle of 140 degree. These two movements are the position of the arm-motion toward the ball.

Performance. Forward or front-set is performed by extending the legs to form an angle of 155 degree and straightening the arms forward at an angle of 136 degree. Push both legs and arms ending with straight fingers with the arms resulting from the flexion of the wrists.

End. The final movement is to bend the legs into 140 degree as an effort to compensate for the forward power of the body and body weight.

\subsection{Backset movement}

Preparation. The player begins the preparatory movement with an upright body position with the angle of the leg bent 90 degree. The result of this movement is that the body is brought under the ball so that the ball is within reach. The elbow flexes at 128 degree and the wrist performs an extension motion at an angle of 156 degree. These two movements are the position of the arm-motion toward the ball.

Performance. Backset is done by bending the body backward in an arc at an angle of 150 degree with straight legs and arms. The arm follows the flex of the body by extending the arm 
up and back at an angle of 123 degree and ending with a straight radius burst with the arm resulting from the flexion of the wrist.

End. The final movement by bending the legs into 120 degree as an effort to compensate the body's power back and body weight so that it is balanced and does not fall.

\subsection{Discussion}

Passing is a specific technique where a good physical condition is required. Seen fast and strong leg movements as a foundation and determine the right body position to reach the ball. Strength and flexibility of the abdomen play an important role in maintaining the balance of motion, even seen dominant in the backset movement. The strength of the arms and fingers as a medium of contact with the ball is important about the ability and speed of the ball to reach the attacking player. The body movements in the preparation, implementation and final stages that are done well and are supported by qualified physical conditions produce good movement and result in the set-up.

\section{$5 \quad$ Result and Discussion}

Based on the results of data analysis, it can be concluded that the movement shows that it approaches the correctness of motion technique. Bouncing the ball that is good for the setupper player results from the mastery of footwork skills, body flexing ability, arms thrust, and finger cracking.

\section{References}

[1] HUANG, Hung-Yu; TENG, Tso-Liang; LIANG, Cho-Chung. Volleyball injuries: a survey of injuries among male players of the Chinese Taipei national volleyball team. Am J Sports Sci, 2015, 3.6: $109-114$.

[2] MISKIN, M., et al. Skill importance in women's volleyball. Journal of Quantitative Analysis in Sports, 2010, 6.2: 1-14.

[3] RAIOLA, Gaetano; DI TORE, Pio Alfredo. Bodily communication skills and its incidence on female volleyball championship to enhance didactics. Journal of Human Sport and Exercise, 2012, 7.2: 365-375.

[4] VIERA, Barbara L.; FERGUSSON, Bonnie Jill. Bola voli tingkat pemula. Jakarta: PT. Rajagrafindo Persada, 2004

[5] BEUTELSTAHL, Dieter. Belajar Bermain Bola Volley. CV. Pionir Jaya, 2005.

[6] JIMENEZ-OLMEDO, Jose Manuel, et al. Serve analysis of professional players in beach volleyball. 2012.

[7] ALEXANDER, Marion, et al. An analysis of the volleyball jump serve. Coach Info,-(0), 2009, 110.

[8] MARQUES, Mário C., et al. Changes in physical parameters performance in starters and nonstarters elite volleyball play-ers: A short report. International Journal of Volleyball Research, 2010, 10.1: 20-25.

[9] EDUCATION, Coach. Coaching volleyball technical and tactical skills. Human Kinetics, 2011.

[10] PATSIAOURAS, Asterios, et al. Technical skills leading in winning or losing volleyball matches during Beijing Olympic Games. Journal of Physical Education and Sport, 2011, 11.2: 149.

[11] VUORINEN, Kasper. Modern volleyball analysis and training periodization. 2018.

[12] PIRAS, Alessandro; LOBIETTI, Roberto; SQUATRITO, Salvatore. Response time, visual search strategy, and anticipatory skills in volleyball players. Journal of Ophthalmology, 2014, 2014. 